\title{
Pathophysiology of the Peritoneal Membrane during Peritoneal Dialysis: The Role of Hyaluronan
}

\author{
Susan Yung and Tak Mao Chan \\ Department of Medicine, The University of Hong Kong, Room 302 New Clinical Building, Queen Mary Hospital, \\ Pokfulam, Hong Kong \\ Correspondence should be addressed to Susan Yung, ssyyung@hku.hk
}

Received 28 June 2011; Revised 11 September 2011; Accepted 12 September 2011

Academic Editor: Beric Henderson

Copyright ( $\odot 2011$ S. Yung and T. M. Chan. This is an open access article distributed under the Creative Commons Attribution License, which permits unrestricted use, distribution, and reproduction in any medium, provided the original work is properly cited.

\begin{abstract}
During peritoneal dialysis (PD), constant exposure of mesothelial cells to bioincompatible PD solutions results in the denudation of the mesothelial monolayer and impairment of mesothelial cell function. Hyaluronan, a major component of extracellular matrices, is synthesized by mesothelial cells and contributes to remesothelialization, maintenance of cell phenotype, and tissue remodeling and provides structural support to the peritoneal membrane. Chronic peritoneal inflammation is observed in longterm PD patients and is associated with increased hyaluronan synthesis. During inflammation, depolymerization of hyaluronan may occur with the generation of hyaluronan fragments. In contrast to native hyaluronan which offers a protective role to the peritoneum, hyaluronan fragments exacerbate inflammatory and fibrotic processes and therefore assist in the destruction of the tissue. This paper will discuss the contribution of mesothelial cells to peritoneal membrane alterations that are induced by PD and the putative role of hyaluronan in these processes.
\end{abstract}

\section{Introduction}

Peritoneal dialysis (PD) is an effective form of renal replacement therapy that is currently used by approximately $11 \%$ of the total global dialysis population. Although PD has greatly improved the quality of life in renal patients, a major disadvantage of this treatment is that PD solutions are bioincompatible since they contain elevated concentrations of glucose to provide the osmotic drive, a low $\mathrm{pH}$ to prevent glucose caramelization during heat sterilization and lactate to correct metabolic acidosis. Heat sterilization of glucosebased PD solutions and storage can give rise to the formation of glucose degradation products (GDPs). Besides their direct toxic effect on mesothelial cells [1], GDPs promote the formation of advanced glycation end products [2]. These constituents have been shown to provoke peritoneal inflammation and injury in mesothelial cells, resulting in structural changes in the peritoneal membrane and progressive loss of peritoneal functions [3-5]. Studies have demonstrated that many patients on long-term PD exhibit reduplication of the basal lamina, increased synthesis and deposition of matrix proteins within the submesothelium, and progressive subendothelial hyalinization, with narrowing or obliteration of the vascular lumen $[6,7]$. These structural changes are exacerbated by episodes of peritonitis and are associated with a loss of ultrafiltration and solute clearance that leads to technique failure and unfavorable clinical outcomes. Specifically how these changes in the peritoneal membrane are regulated remains to be fully elucidated.

Hyaluronan is a large glycosaminoglycan that is constitutively synthesized by mesothelial cells. We and others have demonstrated that hyaluronan plays a crucial role in the maintenance of mesothelial cell morphology and remesothelialization $[8,9]$. While the mechanisms through which hyaluronan participates in peritoneal homeostasis and pathological processes are being investigated, there is accumulating data to show that the hyaluronan molecule can exert either protective or potentially destructive effects depending on its molecular weight, local concentration, and tissue distribution. This paper will focus on the putative role 
of hyaluronan in peritoneal homeostasis and how alterations in hyaluronan synthesis induced by PD can contribute to peritoneal inflammation, EMT, and fibrosis.

\section{Peritoneal Mesothelial Cells}

The peritoneal membrane consists of a monolayer of mesothelial cells underneath which contains the submesothelium, fibroblasts, collagen fibrils, and capillaries [10]. Peritoneal mesothelial cells are specialized epithelial cells that line the peritoneal cavity. Although previously thought to function solely as a lubricating, nonadhesive surface to facilitate intracoelomic movement, there is now compelling evidence to demonstrate that peritoneal mesothelial cells are not passive cells but play critical roles in peritoneal homeostasis, maintenance of peritoneal membrane integrity, fluid, and solute transport, peritoneal inflammation, and wound healing. Mesothelial cells regulate peritoneal inflammation and tissue remodeling by virtue of their ability to synthesize a plethora of cytokines, growth factors, and matrix proteins [11-14]. Mesothelial cells also synthesize glycosaminoglycans and proteoglycans such as hyaluronan, decorin, syndecan- 1 , and perlecan that endow the mesothelium with a protective glycocalyx and selective permeability property [15-24].

Although mesothelial cells are derived from the mesoderm, they possess many features of epithelial cells that include a polygonal, cobblestone morphology with surface microvilli, are situated on a basement membrane, express cytokeratin, and have the ability to form a polarized monolayer that permits translocation of molecules to either the apical or basolateral aspect of the cells [25-29]. Cell polarity is essential to maintain normal mesothelial cell function and occurs upon cell-cell contact. The precise distribution of proteins to the apical or basolateral aspect of the cell is critical for cell signaling and interaction with their microenvironment. With regard to their mesenchymal characteristics, mesothelial cells can express vimentin, desmin, and $\alpha$ smooth muscle actin, the latter induced during cell activation [25, 29-31]. Mesothelial cells are connected by intercellular junctions (tight junctions, gap junctions, adherens junctions, and desmosomes) that contribute to the establishment and maintenance of a continuous mesothelial monolayer [32]. Mesothelial cells have been shown to express ZO1 , occluding, and claudin-1 [33,34]. Reduced expression of adherens junctions during pathologic conditions or inflammatory processes is associated with a collapse of cellcell communication and cell-matrix interaction resulting in the denudation of the mesothelium, a process that is often observed during PD $[33,34]$.

Since an in-depth discussion on mesothelial cell structure and function is beyond the scope of this paper, the reader is referred to the related reviews [26, 27, 35-37].

\section{Hyaluronan}

Hyaluronan is a negatively charged, linear polysaccharide that is widely distributed in epithelial, connective, and neural tissues [38, 39]. Unlike other glycosaminoglycans, it is neither sulfated nor is it attached to a protein core. It is composed of repeating disaccharide units of D-glucuronic acid and $\mathrm{N}$-acetyl-D-glucosamine and is synthesized on the inner surface of plasma membranes by uridine diphosphate glucose dehydrogenase and one of three related hyaluronan synthases (HAS), namely, HAS I, II, or III [40]. These isoenzymes have a $55-70 \%$ homology, and HAS II is critical for animal survival [41]. HAS I is the least active of the HAS isoenzymes and together with HAS II controls the synthesis of high molecular weight (HMW) or native hyaluronan. HAS II is more active than HAS I, and its upregulation is implicated in wound healing, inflammation, and tissue growth. Of the 3 isozymes, HAS III is the most active and drives the synthesis of low molecular weight (LMW) hyaluronan. Given that HAS I, II, and III expressions are differentially regulated by cytokines and growth factors [42], it is plausible to suggest that depending on the inciting factor, one or more HAS isoforms may be upregulated to induce hyaluronan synthesis of different molecular weights and abundance.

Under physiologic conditions, hyaluronan is synthesized as a macromolecule with a molecular weight in excess of $10^{6} \mathrm{Da}$ [43]. Following its synthesis, hyaluronan is directed to the cell surface where it interacts with its receptor CD44 or it is assembled into the pericellular matrix (glycocalyx) or extracellular matrix (ECM). The regulation of hyaluronan translocation to the different compartments of the cell is currently unknown, but it is possible that mechanisms used to export other polysaccharides may be involved such as the adenosine- $5^{\prime}$-triphosphate-binding cassette system. Despite its simple structure, hyaluronan is a multifaceted molecule that contributes to the structural integrity of tissues, maintains water balance, assists in the distribution and transport of plasma proteins, promotes cell quiescent, decreases fibrotic mediators, and possesses anti-inflammatory properties [44-46]. Due to its ability to regulate cell proliferation, migration and phenotype, and cell-cell communication, hyaluronan also plays a pivotal role in metastasis and tumorigenesis [47-49]. Hyaluronan can influence physiologic cell behavior through three mechanisms. Firstly, hyaluronan can form tertiary structures in aqueous solutions and interact with water molecules resulting in the production of a hydrated environment with high viscosity and elasticity that allows cells to divide and migrate [50]. Secondly, hyaluronan contributes to the assembly and structural integrity of pericellular matrices, which influence cell shape during cell division, movement, and morphogenesis [51]. Thirdly, hyaluronan can influence cell behavior through its interaction with its cell surface receptors, namely, CD44 or receptor for hyaluronan-mediated motility, and initiate intracellular signaling $[52,53]$.

HMW hyaluronan undergo constant turnover during the daily maintenance of basement membranes, and its degradation into small, nonbiologically active fragments is rapidly removed from the body by the liver. In chronic inflammation, elevated serum levels of hyaluronan and its deposition at sites of injury are often observed. The accumulation of hyaluronan in tissues has been shown to exacerbate inflammatory processes. Fragmentation of ECM components often occurs during tissue injury, and these fragments possess functional properties that are distinct from 
TABLE 1: Functions of native hyaluronan and its fragments during tissue homeostasis and inflammation.

\begin{tabular}{ll}
\hline HMW hyaluronan & LMW hyaluronan \\
\hline $\begin{array}{l}\text { Contributes to the protective role of the glycocalyx, acts as a } \\
\text { lubricant }\end{array}$ & $\begin{array}{l}\text { Induces chemokine and cytokine secretion by infiltrating, } \\
\text { mesothelial, renal tubular epithelial and endothelial cells }\end{array}$ \\
$\begin{array}{l}\text { Transportation and distribution of plasma proteins } \\
\text { Contributes to water balance and regulation of tissue hydration }\end{array}$ & $\begin{array}{l}\text { Induces phosphorylation of signaling pathways, for example, MAPK } \\
\text { Induces cell migration, for example, tumor cells }\end{array}$ \\
$\begin{array}{l}\text { Contributes to tissue integrity and maintenance of epithelial cell } \\
\text { phenotype }\end{array}$ & $\begin{array}{l}\text { Induces cell proliferation in chondrocytes, endothelial cells, and } \\
\text { fibroblasts }\end{array}$ \\
$\begin{array}{l}\text { Protects against tissue damage by scavenging free radicals } \\
\text { Protects against apoptosis }\end{array}$ & $\begin{array}{l}\text { Activates NF } \kappa \text { B } \\
\text { Antiangiogenic }\end{array}$ \\
$\begin{array}{l}\text { Inhibits phagoces nitric oxide synthase } \\
\text { Anti-inflammatory, can inhibit activation of inflammatory cells }\end{array}$ & $\begin{array}{l}\text { Promotes angiogenesis } \\
\text { Increases matrix protein synthesis, for example, collagen type I }\end{array}$ \\
Promotes cell quiescence & Suppresses cell death and apoptosis in cell culture \\
Immunosuppressive (prevents ligand binding to surface receptors) & Induces heat-shock protein expression \\
\hline
\end{tabular}

LMW hyaluronan: ranges from 4 to 40 saccharide units.

their parent molecule [46]. The clearance of ECM fragments is therefore imperative for the resolution of tissue injury. Independent researchers have suggested that LMW hyaluronan may deposit in inflamed tissues consequent to their de novo synthesis or through the depolymerization of native hyaluronan following increased activity of hyaluronidase or reactive oxygen species $[46,54,55]$. Unlike native hyaluronan, hyaluronan fragments have been shown to promote angiogenesis, induce multiple signaling cascades, and increase cell proliferation, cytokine secretion, matrix metalloproteinase (MMP) activity, and matrix protein synthesis in murine models of lung disease or cultured mesothelial and endothelial cells, keratinocytes, macrophages, and dendritic cells [46, 56-62]. Proinflammatory cytokines and profibrotic growth factors have been shown to increase synthesis of both HMW and LMW hyaluronan in various cell types [63-66]. Table 1 summarizes the distinct roles of HMW and LMW hyaluronan under physiologic and inflammatory conditions. Despite numerous articles highlighting the inflammatory properties of LMW hyaluronan in vitro or ex vivo, one must take note that reports detailing the actual appearance of LMW hyaluronan in tissues undergoing inflammation are limited [67]. The lack of antibodies that distinguishes between native HA and its fragments may, in part, contribute to this paucity of data, and therefore in-depth biochemical methodologies are warranted to provide evidence of their presence at sites of inflammation and tissue injury.

\section{The Role of Hyaluronan in the Maintenance of the Normal Peritoneal Membrane}

In the healthy individual, a thin film of fluid is found on the surface of mesothelial cells, which serves as a lubricant for the peritoneal viscera that protects the mesothelial surface from abrasions and adhesions. This fluid constitutes the glycocalyx and contains a number of macromolecules that include lipoproteins, phospholipids, and hyaluronan. The integrity of the glycocalyx is, in part, attributed to the presence of HMW hyaluronan $[68,69]$. The glycocalyx contributes to the protective, nonadhesive nature of the mesothelial cell surface and plays an important role in cell-cell contact, tissue integrity and hydration, regulation of inflammation, wound healing, and flow of nutrients and growth factors across the peritoneal membrane [70]. The luminal surface of mesothelial cells is endowed with microvilli [28]. Microvilli entrap water and serous exudates, which protect the delicate surface of mesothelial cells from frictional damage [27]. Microvilli allows mesothelial cells to sense their microenvironment and also functions to entrap bacteria thereby preventing infection. The density of microvilli on regenerating mesothelial cells may vary and is dependent on the anionic charge of the glycocalyx [28]. Recent studies have demonstrated that the presence of hyaluronan in the glycocalyx of MCF-7 cells is essential for the formation of microvilli and that the length of these protrusions is dependent on HAS activity and the rate of hyaluronan synthesis [71]. The removal of hyaluronan from microvilli following treatment with hyaluronidase is accompanied by their retraction from the cell surface [71]. The synthesis of microvilli on mesothelial cells has not been fully investigated, but it is possible that it is regulated by hyaluronan as observed in MCF-7 cells. The presence of microvilli on the surface of mesothelial cells can increase the surface area of the peritoneal membrane available for peritoneal transport from $2 \mathrm{~m}^{2}$ to $40 \mathrm{~m}^{2}$. A reduction in the number of microvilli on mesothelial cells would therefore have a profound effect on peritoneal function and transport.

The peritoneal mesothelium provides the first line of defense against bacteria, chemical, or surgical insult. It is therefore essential that following injury and denudation, rapid restoration of the mesothelial monolayer takes place. The mechanism through which the normal mesothelium is restored is controversial and has been suggested to involve centripedal migration of mesothelial cells as observed in the squamous epithelium, exfoliation of healthy mesothelial cells from neighboring sites which settle on the denuded area, 
free-floating reserve cells, submesothelial and bone-marrowderived precursor cells, and macrophage transformation [27, 72-79].

We and others have shown that mesothelial cells synthesize large quantities of hyaluronan that is secreted into their microenvironment or can be found on the mesothelial cell surface as a major constituent of the mesothelial glycocalyx [16-18, 63, 80]. Hyaluronan plays an essential role in peritoneal homeostasis, but changes in hyaluronan synthesis and its interaction with its cell surface receptors can have a profound effect on cell function. Increased hyaluronan synthesis in mesothelial cells is associated with increased cell migration, proliferation, and phenotypic changes $[47,81]$. Using an established in vitro model of wound healing, we have demonstrated that, following mechanical denudation of the mesothelial monolayer, repopulation of the monolayer is mediated by the migration of mesothelial cells from the leading edge of the wound into the denuded area [8]. This process is accompanied by a loss of cell-cell contact at the wound margin and induction of epithelial-to-mesenchymal transdifferentiation (EMT), a reversible process that bestows upon mesothelial cells a migratory, invasive fibroblastic phenotype and is accompanied by the dissolution of intercellular junctions, loss of cell polarity, reorganization of the cytoskeleton and focal adhesion components, and increased synthesis of matrix proteins and hyaluronan, the latter observed predominantly in migratory, elongated mesothelial cells $[8,82]$. The increase in hyaluronan synthesis during remesothelialization was mediated through an increase in HAS II mRNA expression with a concomitant decrease in HAS III expression [8]. The ability of mesothelial cells to manifest features of mesenchyme underscores the plasticity property of these cells. The early phase of remesothelialization was dependent primarily on cell migration, and cell proliferation was observed during the latter part of mesothelial replenishment. Mesothelial cells reassumed their cobblestone, epithelial morphology once the monolayer was reestablished and cell-cell contact restored, and this was associated with a decrease in hyaluronan synthesis. The importance of hyaluronan in mesothelial regeneration was highlighted in separate studies, whereby the rate of remesothelialization increased with rising concentration of exogenous hyaluronan added to the denuded monolayer [8]. The significance of hyaluronan in reepithelialization and wound healing was corroborated in the skin and shown to depend on its interaction with its cell surface receptor CD44, since interference of hyaluronan-CD44 interaction resulted in delayed wound healing and defective skin elasticity [83].

\section{The Effect of PD on Hyaluronan Synthesis and Mesothelial Cell Function}

Acute inflammation is a defense mechanism that has evolved in response to tissue injury. It is characterized by increased vascular permeability, cell infiltration to sites of injury, release of inflammatory mediators by both resident and infiltrating cells, and increased matrix turnover. Although inflammation may initiate temporary tissue damage, subsequent reparative processes promote the resolution of in- flammation. Repeated insult to the peritoneal membrane as observed in PD, however, disturbs the reparative process, which results in chronic inflammation and subsequent destruction of the tissue.

\subsection{PD Increases Hyaluronan Synthesis in Mesothelial Cells.} Hyaluronan is often used as a surrogate marker of inflammation. We and others have demonstrated that low levels of hyaluronan can be detected in dialysis effluent obtained from noninfected PD patients and that these levels are significantly increased in PD patients with peritonitis [16, 80]. Our observation that serum hyaluronan levels did not differ between noninfected and infected PD patients and that dialysate hyaluronan levels are almost 2- and 10-folds higher that the corresponding serum levels in noninfected and infected PD patients, respectively, would imply that local production accounts for the hyaluronan detected in PD fluid [16]. Biochemical analysis of hyaluronan purified from noninfected and infected dialysis effluent showed it to be of a HMW with a hydrodynamic size of 0.75 as determined by Sephacryl-S1000 gel filtration [16]. We have demonstrated that over $90 \%$ of hyaluronan synthesized by cultured mesothelial cells under basal conditions is secreted into their culture medium and its molecular weight is identical to that detected in PD fluid. This together with our observation that both noninfected and infected PD fluids can induce de novo synthesis of hyaluronan in mesothelial cells would indicate that mesothelial cells are a likely source of dialysate hyaluronan [16].

The molecular weight of hyaluronan retained on the surface of mesothelial cells is larger than that secreted suggesting partial depolymerization of the parent molecule as it is released from the plasma membrane [16]. Once released by mesothelial cells, hyaluronan appears stable and does not further undergo fragmentation in the peritoneal cavity despite ongoing peritoneal inflammation [16]. Increased synthesis of hyaluronan in mesothelial cells during peritonitis is attributed to pro-inflammatory cytokines and growth factors, in particular IL- $\beta[63,80]$. The inability to detect hyaluronan fragments in spent PD fluids corroborates previous reports that LMW hyaluronan is not observed in situ [84].

5.2. Altered Hyaluronan Content in the Mesothelial Glycocalyx during PD. Commencement of PD in patients with endstage renal disease is associated with the dilution of the glycocalyx's constituents and their subsequent removal from the peritoneal cavity with each exchange of PD fluid. A loss of the protective glycocalyx surrounding mesothelial cells would imply increased susceptibility of these cells to the detrimental effect of PD fluids. Studies have demonstrated that disruption of the glycocalyx in human smooth muscle cells using hyaluronan oligosaccharides inhibited cell migration and proliferation and resulted in a marked change to their morphology with the appearance of a flattened, more adherence phenotype [51]. We and others have demonstrated that PD fluid or its constituents can induce senescence in cultured mesothelial cells and such cells can also be isolated from spent PD fluid [26, 85-88]. Mesothelial cells with a senescent 
phenotype have reduced cell proliferation, are more adherent to their substrate, and have increased fibrogenic properties $[87,89,90]$. Furthermore, ultrastructural studies have highlighted a reduction in the number and length of microvilli on these senescent cells compared to normal mesothelial cells [90]. Since hyaluronan plays a crucial role in the formation of microvilli, the unphysiological concentration of glucose in PD solutions could exert its harmful effects through altered hyaluronan synthesis and/or increased release from the mesothelial glycocalyx into the peritoneal cavity, and such effects would result in phenotypic changes and altered cellular functions. The observed increase in hyaluronan levels in dialysis effluent may in part be attributed to its release from the mesothelial glycocalyx. In line with this suggestion, hyperglycemia has been shown to reduce the volume of the endothelial glycocalyx in diabetic patients, which was associated with increased release of glycocalyx constituents into the circulation and perturbed vascular functions [91].

The importance of hyaluronan in maintaining the structural and functional integrity of the peritoneum during PD is highlighted in rat models of PD in which hyaluronan supplementation significantly reduced peritoneal inflammation, preserved the structural integrity of the peritoneum, and improved ultrafiltration and membrane transport functions [92-96]. Furthermore, in vitro studies whereby peritoneal mesothelial cells were incubated with exogenous HMW hyaluronan resulted in reduced secretion of fibronectin and inflammatory mediators, thus confirming the antiinflammatory and antifibrotic properties of hyaluronan [97]. Hyaluronan supplementation may replenish peritoneal levels of hyaluronan and decrease the hydraulic conductivity of the submesothelium, thereby preventing PD fluid absorption $[95,98]$.

\subsection{PD Increases Submesothelial Expression of Hyaluronan.} In a recent study, Osada et al. assessed the intraperitoneal expression of hyaluronan in PD patients and healthy controls [99]. These researchers observed a weak expression of hyaluronan in the peritoneum of healthy subjects, whilst increased expression of hyaluronan was noted in the submesothelium of uremic patients who had just entered the PD program. Submesothelial expression of hyaluronan was further increased in chronic PD patients and also in patients who had developed peritonitis [99]. Although Osada et al. did not investigate the mechanism that resulted in an increase in intraperitoneal expression of hyaluronan, it may be attributed to increased levels of proinflammatory and fibrotic cytokines in the peritoneal cavity $[14,100-102]$ since PDGF, IL- $1 \beta$, IL-6, TNF- $\alpha$, and TGF- $\beta 1$ have all been shown to increase hyaluronan secretion in cultured mesothelial cells and fibroblasts $[18,63]$. Overexpression of hyaluronan is indicative of a breakdown in the fine balance between synthesis and degradation. These researchers did not provide any details of hyaluronan expression in the mesothelium, the molecular weight of hyaluronan expressed within the submesothelium, nor HAS activity in the peritoneum, and we were unable to determine whether peritoneal specimens used in their study were partially or completely devoid of a mesothelium, a phenomenon frequently observed in PD patients [6]. Changes in the submesothelium has been shown to precede the loss of the mesothelium in PD patients and is associated with peritoneal fibrosis and vasculopathy [6]. Is it therefore possible for increased submesothelial expression of hyaluronan to induce mesothelial denudation and peritoneal fibrosis? In an attempt to answer this, one must first explore the mechanism that upholds the integrity of an epithelial monolayer and the consequences of altered cell phenotype and subsequent pathologic EMT, with particular focus on hyaluronan in these processes.

\subsection{Putative Role of Hyaluronan in EMT and Peritoneal} Fibrosis. The expression of E-cadherin is a cardinal feature of epithelial monolayers [103, 104]. A loss of E-cadherin at the intercellular junctions is strongly associated with epithelial dedifferentiation, phenotypic alterations, and induction of EMT. E-cadherin is a calcium-dependent transmembrane glycoprotein that is localized at the basolateral membrane in adherens junctions and endows epithelial cells with their apicobasolateral polarity $[104,105]$. E-cadherin is a suppressor of CD44-hyaluronan interactions and has been shown to prevent epithelial dedifferentiation and subsequent EMT [106]. A balance between E-cadherin and CD44-hyaluronan is therefore essential to maintain normal epithelial cell integity and function. In the setting of $\mathrm{PD}$, decreased expression of ZO-1, E-cadherin, and $\beta$-catenin is observed in cultured mesothelial cells upon stimulation with elevated glucose concentration [33]. A reduction in E-cadherin expression in mesothelial cells would indicate a loss of the cells' ability to suppress hyaluronan expression. We have previously demonstrated that increased hyaluronan expression is critical for inducing EMT in mesothelial cells during wound healing and tissue repair but, once the mesothelial monolayer is replenished, hyaluronan levels return to constitutive levels [8]. The persistent increase in intraperitoneal expression of hyaluronan during PD would suggest that mesothelial cells are sustained in an activated fibroblastic phenotype (pathologic EMT) and mesenchymal-to-epithelial transdifferentiation is inhibited. Increased production of hyaluronan and its accumulation in the ECM has been shown to diminish contact inhibition in nontransformed rat 3Y1 cells [52], thereby underscoring the importance of hyaluronan in physiologic and pathologic EMT. Under physiological conditions, epithelial cells will undergo apoptosis if they are detached from their substratum [107]. However, epithelial cells that have undergone EMT have developed specific mechanisms that allow them to survive as anchorage-independent cells without cell-cell interactions [53]. Emerging evidence suggests that hyaluronan triggers numerous signaling pathways that promote cell survival of transdifferentiated cells [108]. The acquisition of a migratory and invasive phenotype allows mesothelial cells to migrate into the submesothelium following the disruption of the basement membrane, which is made possible by the increased production and activity of MMPs [86]. Transdifferentiated mesothelial cells adopt a more fibrogenic characteristic that allows them to contribute to the thickening of the submesothelium and subsequent peritoneal fibrosis $[109,110]$. The migration of mesothelial cells into 


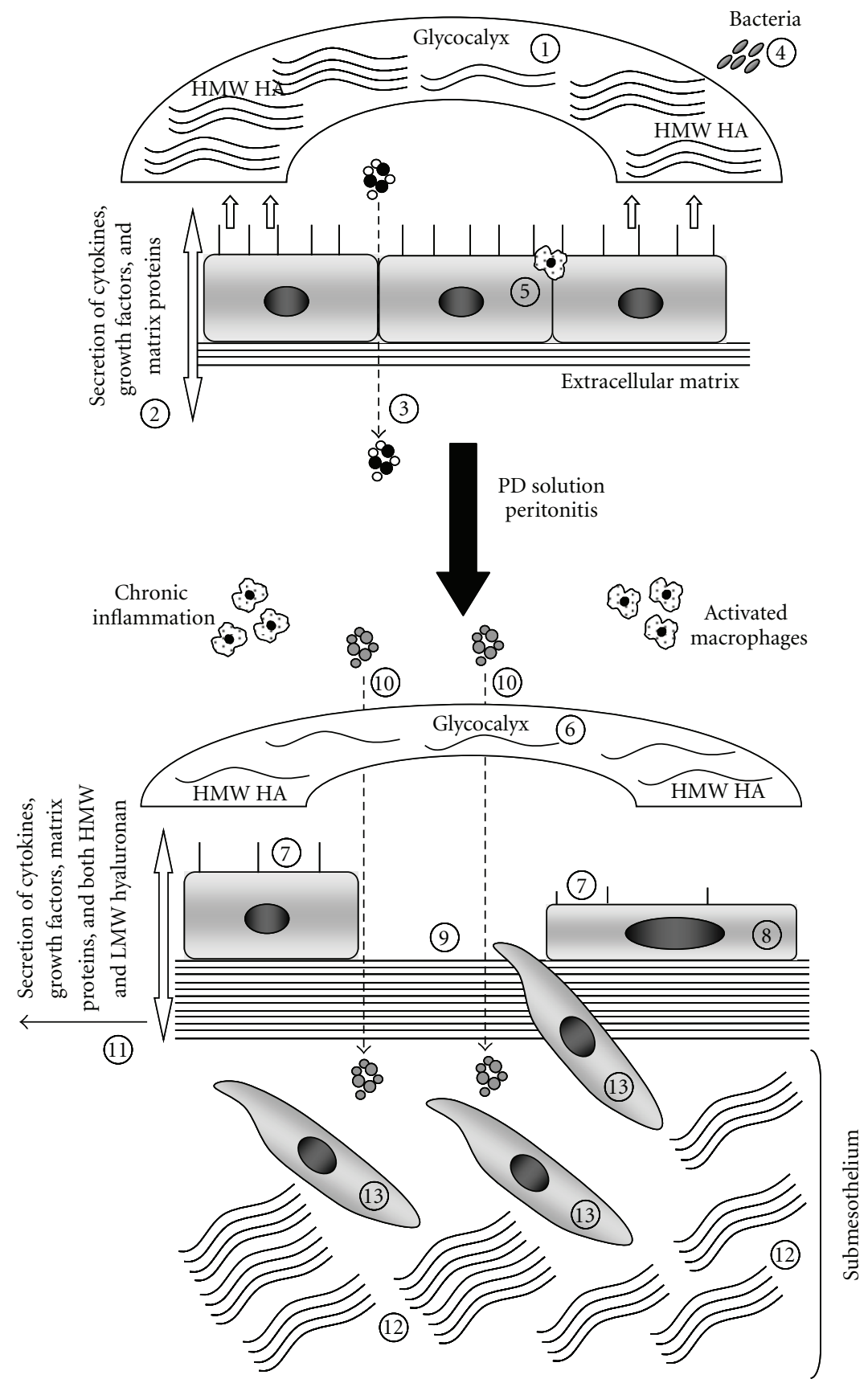

FIgure 1: Changes to hyaluronan synthesis during PD alter mesothelial cell functions. The mesothelium contributes to peritoneal homeostasis. Under physiologic conditions, mesothelial cells secrete HMW hyaluronan which is the main constituent of the glycocalyx. The glycocalyx surrounds the apical surface of mesothelial cells and provides a protective barrier against abrasion, and a slippery, nonadhesion surface for intracoelomic movement (1). Mesothelial cells participate in tissue repair and in the induction and resolution of peritoneal inflammation through their ability to synthesize cytokines and growth factors that are secreted into the peritoneal cavity (2). Mesothelial cells also synthesize matrix proteins which provide a substratum onto which mesothelial cells adhere (2). Mesothelial cells facilitate the transport of fluids and solutes across the peritoneal membrane (3), are the first line of defense against bacterial peritonitis (4), and can maintain a chemotactic gradient to assist in leukocyte infiltration (5) during bacterial, chemical, or surgical insult. Changes to the peritoneum following the initiation of PD. Constant exposure of the peritoneal membrane to bioincompatible PD solution results in either a reduction of the glycocalyx volume (6) or its complete depletion from the surface of mesothelial cells. Changes in the content of hyaluronan in the peritoneum can induce morphologic and phenotypic changes to mesothelial cells that include reduced length and density of microvilli on the surface of mesothelial cells (7), generation of senescent cells (8), and frequent denudation of the mesothelium (9), thereby allowing PD solutions to leak into the submesothelium causing peritoneal injury (10). Activation of both immune cells and mesothelial cells further increases synthesis of cytokines and growth factors (11), which exacerbates peritoneal inflammation, fibrogenesis, and increases submesothelial expression of HMW hyaluronan (12). Activation of mesothelial cells induces EMT (13), breakdown of the basement membrane, and their migration into the submesothelium. Communication of activated mesothelial cells with peritoneal fibroblasts and endothelial cells may provoke further inflammatory and fibrotic processes in the submesothelium resulting ultimately in peritoneal fibrosis. 
the submesothelium may also contribute to the denudation of the mesothelium, mediated in part through increased bioactivation of TGF- $\beta 1$, a key mediator of tissue fibrosis [110]. An inability to restore the mesothelial monolayer is associated with unfavorable structural and functional changes in the peritoneal membrane of PD patients [6].

What is the functional role of hyaluronan in the submesothelium? Unfortunately, it is not possible to provide direct evidence of its contributing role to peritoneal fibrosis due to a lack of research in this area. Nevertheless, by extrapolating data from other studies, one may conceive that sustained increase in intraperitoneal expression of hyaluronan prolongs pathologic EMT and inflammation leading ultimately to peritoneal fibrosis. In this respect, high-molecular-weight hyaluronan has been demonstrated to induce Snail2 in NIH-3T3 mouse fibroblasts, which endow the cells with an increased invasive activity [111]. HMW hyaluronan has also been shown to upregulate MMP activity in lymphoma cell lines and metastatic tumor cells through the prior induction of NF $\kappa \mathrm{B}$ [112]. Accumulation of hyaluronan in keratocytes mediates TGF- $\beta 1$ induction of $\alpha$-smooth muscle actin and matrix protein synthesis [62]. That hyaluronan can augment fibrotic processes is corroborated by the observation that gene silencing of HAS II or removal of hyaluronan by digestion with hyaluronidase inhibited TGF- $\beta 1$-induced $\alpha$ smooth muscle and fibronectin mRNA [62]. Taken together, these data would suggest that overexpression of hyaluronan plays a critical role in the induction of cell activation and tissue fibrosis, its transformation from a molecule that can exert a beneficial effect on tissue homeostasis to one that mediates tissue injury is dependent largely on its tissue concentration, localization, and molecular weight.

\section{Hyaluronan as a Surrogate Marker for Peritoneal Inflammation}

Deleterious changes to the structural integrity of the peritoneal membrane are often associated with a loss of dialytic potential in PD patients, which can lead to technique failure. Thickening of the submesothelium is a consistent observation in PD patients [6]. Studies have highlighted that the bioincompatible nature of PD solutions is a major instigator of EMT and peritoneal fibrosis. Although examination of peritoneal biopsies allows clinicians to monitor morphologic changes in the peritoneal membrane with time on $\mathrm{PD}$, this method is invasive and cannot be performed frequently. The measurement of pro-/anti-inflammatory and fibrotic markers in dialysate effluent has provided researchers with a noninvasive method to indirectly assess the physical condition of the peritoneum with time. The measurement of hyaluronan in spent PD solutions provides researchers and clinicians with an indication of the degree of peritoneal inflammation with time and treatment regimens. In a quest to preserve the functional properties of the peritoneal membrane, new PD solutions have been developed that use amino acids or icodextrin as the osmotic agent instead of glucose or the partial substitution of lactate with bicarbonate [113-115]. The use of alternative PD fluids is associated with a reduction of proinflammatory mediators such as hyaluronan and a concomitant increase in CA125 levels, a marker of mesothelial cell mass and peritoneal membrane integrity $[101,102,116,117]$.

The levels of hyaluronan in biological fluids are a good indicator of numerous diseases and inflammation. Studies have demonstrated strong correlations between serum hyaluronan levels and the degree of impaired renal function $[118,119]$. Increased serum levels of hyaluronan have also been shown to predict mortality and morbidity in PD patients [120], whereas dialysate levels of hyaluronan can predict survival in PD patients [121].

\section{Conclusion}

PD is an effective modality of renal replacement therapy for patients with end-stage renal disease, but, due to the bioincompatible nature of PD solutions, a chronic inflammatory response is generally observed within the peritoneal cavity, which jeopardizes the structural and functional integrity of the peritoneal membrane. Structural changes begin with the modification of the mesothelial monolayer, with a loss of microvilli, widening of the intracellular gap junctions, loss of E-cadherin, the adoption of a migratory, fibroblastic phenotype, and induction of EMT, which progress to peritoneal fibrosis. Studies have demonstrated that each of these processes is regulated or influenced by hyaluronan. It is intriguing that different molecular weights or concentrations of hyaluronan could result in distinct effects on biological processes. Pathologic changes in the peritoneum are attributed solely to HMW hyaluronan and not its fragments. Our knowledge of the contributing role of hyaluronan in peritoneal homeostasis and pathology, its interaction with its binding proteins, and how its synthesis is modulated during inflammation and fibrosis is far from complete. It is envisaged that, with time, we may unravel the many mysteries of hyaluronan, which will allow us to devise novel therapeutic interventions to preserve the structural and functional integrity of the peritoneum and thereby improving patient survival on PD.

Figure 1 shows a schematic diagram that details the current understanding of how hyaluronan protects the peritoneum during peritoneal homeostasis (upper panel) and how changes to its level and localization can mediate changes to mesothelial phenotype, function, and induce peritoneal injury in the setting of PD (lower panel).

\section{Acknowledgments}

Part of this work was supported by the Wai Hung Charitable Foundation and the Estate of the late Mr. Chan Wing Hei.

\section{References}

[1] J. Witowski, J. Wisniewska, K. Korybalska et al., "Prolonged exposure to glucose degradation products impairs viability and function of human peritoneal mesothelial cells," Journal of the American Society of Nephrology, vol. 12, no. 11, pp. 2434-2441, 2001. 
[2] A. Tauer, X. Zhang, T. P. Schaub et al., "Formation of advanced glycation end products during CAPD," American Journal of Kidney Diseases, vol. 41, no. 3, pp. S57-S60, 2003.

[3] L. W. Morgan, A. Wieslander, M. Davies et al., "Glucose degradation products (GDP) retard remesothelialization independently of D-glucose concentration," Kidney International, vol. 64, no. 5, pp. 1854-1866, 2003.

[4] V. Schwenger, C. Morath, A. Salava et al., "Damage to the peritoneal membrane by glucose degradation products is mediated by the receptor for advanced glycation end-products," Journal of the American Society of Nephrology, vol. 17, no. 1, pp. 199-207, 2006.

[5] E. Boulanger, M. P. Wautier, J. L. Wautier et al., "AGEs bind to mesothelial cells via RAGE and stimulate VCAM-1 expression,” Kidney International, vol. 61, no. 1, pp. 148-156, 2002.

[6] J. D. Williams, K. J. Craig, N. Topley et al., "Morphologic changes in the peritoneal membrane of patients with renal disease," Journal of the American Society of Nephrology, vol. 13, no. 2, pp. 470-479, 2002.

[7] K. Honda, K. Nitta, S. Horita, W. Yumura, and H. Nihei, "Morphological changes in the peritoneal vasculature of patients on CAPD with ultrafiltration failure," Nephron, vol. 72, no. 2, pp. 171-176, 1996.

[8] S. Yung, G. J. Thomas, and M. Davies, "Induction of hyaluronan metabolism after mechanical injury of human peritoneal mesothelial cells in vitro," Kidney International, vol. 58, no. 5, pp. 1953-1962, 2000.

[9] T. Horiuchi, K. Miyamoto, S. Miyamoto et al., "Image analysis of remesothelialization following chemical wounding of cultured human peritoneal mesothelial cells: the role of hyaluronan synthesis," Kidney International, vol. 64, no. 6, pp. 2280-2290, 2003.

[10] J. Dobbie, "Ultrastructure and pathology of the peritoneum in peritoneal dialysis," in Textbook of Peritoneal Dialysis, R. Gokal, Ed., pp. 17-44, Kluwer Academic, Dodrecht, The Netherlands, 1994.

[11] T. M. Chan, J. K. H. Leung, R. C. W. Tsang, Z. H. Liu, L. S. Li, and S. Yung, "Emodin ameliorates glucose-induced matrix synthesis in human peritoneal mesothelial cells," Kidney International, vol. 64, no. 2, pp. 519-533, 2003.

[12] P. C. Ferriola and W. Stewart, "Fibronectin expression and organization in mesothelial and mesothelioma cells," American Journal of Physiology, vol. 271, no. 5, pp. L804-L812, 1996.

[13] C. C. Fang, C. J. Yen, Y. M. Chen et al., "Pentoxifylline inhibits human peritoneal mesothelial cell growth and collagen synthesis: effects on TGF- $\beta$," Kidney International, vol. 57, no. 6, pp. 2626-2633, 2000.

[14] H. Ha, M. K. Cha, H. N. Choi, and H. B. Lee, "Effects of peritoneal dialysis solutions on the secretion of growth factors and extracellular matrix proteins by human peritoneal mesothelial cells," Peritoneal Dialysis International, vol. 22, no. 2, pp. 171-177, 2002.

[15] P. Heldin and H. Pertoft, "Synthesis and assembly of the hyaluronan-containing coats around normal human mesothelial cells," Experimental Cell Research, vol. 208, no. 2, pp. 422-429, 1993.

[16] S. Yung, G. A. Coles, J. D. Williams, and M. Davies, "The source and possible significance of hyaluronan in the peritoneal cavity," Kidney International, vol. 46, no. 2, pp. 527-533, 1994.

[17] A. Breborowicz, K. Korybalska, A. Grzybowski, K. Wieczorowska-Tobis, L. Martis, and D. G. Oreopoulos, "Synthesis of hyaluronic acid by human peritoneal mesothelial cells: effect of cytokines and dialysate," Peritoneal Dialysis International, vol. 16, no. 4, pp. 374-378, 1996.

[18] A. Breborowicz, J. Wisniewska, A. Polubinska, K. Wieczorowska-Tobis, L. Martis, and D. G. Oreopoulos, "Role of Peritoneal Mesothelial cells and fibroblasts in the synthesis of hyaluronan during peritoneal dialysis," Peritoneal Dialysis International, vol. 18, no. 4, pp. 382-386, 1998.

[19] M. Davies, E. Stylianou, S. Yung, G. J. Thomas, G. A. Coles, and J. D. Williams, "Proteoglycans of CAPD-dialysate fluid and mesothelium," Contributions to Nephrology, vol. 85, pp. 134-141, 1990.

[20] S. Yung, G. J. Thomas, E. Stylianou, J. D. Williams, G. A. Coles, and M. Davies, "Source of peritoneal proteoglycans: human peritoneal mesothelial cells synthesize and secrete mainly small dermatan sulfate proteoglycans," American Journal of Pathology, vol. 146, no. 2, pp. 520-529, 1995.

[21] S. Yung, X. R. Chen, R. C. W. Tsang, Q. Zhang, and T. M. Chan, "Reduction of perlecan synthesis and induction of TGF-beta1 in human peritoneal mesothelial cells due to high dialysate glucose concentration: implication in peritoneal dialysis," Journal of the American Society of Nephrology, vol. 15, no. 5, pp. 1178-1188, 2004.

[22] S. Yung and T. M. Chan, "Hyaluronan-regulator and initiator of peritoneal inflammation and remodeling," International Journal of Artificial Organs, vol. 30, no. 6, pp. 477483, 2007.

[23] S. Yung and T. M. Chan, "Glycosaminoglycans and proteoglycans: overlooked entities?" Peritoneal Dialysis International, vol. 27, supplement 2, pp. S104-S109, 2007.

[24] S. Yung and T. M. Chan, "Peritoneal proteoglycans: much more than ground substance," Peritoneal Dialysis International, vol. 27, no. 4, pp. 375-390, 2007.

[25] E. Stylianou, L. A. Jenner, M. Davies, G. A. Coles, and J. D. Williams, "Isolation, culture and characterization of human peritoneal mesothelial cells," Kidney International, vol. 37, no. 6, pp. 1563-1570, 1990.

[26] S. Yung, F. K. Li, and T. M. Chan, "Peritoneal mesothelial cell culture and biology," Peritoneal Dialysis International, vol. 26, no. 2, pp. 162-173, 2006.

[27] S. E. Mutsaers, "Mesothelial cells: their structure, function and role in serosal repair," Respirology, vol. 7, no. 3, pp. 171191, 2002.

[28] S. E. Mutsaers, D. Whitaker, and J. M. Papadimitriou, "Changes in the concentration of microvilli on the free surface of healing mesothelium are associated with alterations in surface membrane charge," Journal of Pathology, vol. 180, no. 3, pp. 333-339, 1996.

[29] J. T. Hjelle, B. T. Golinska, D. C. Waters, K. R. Steidley, D. R. McCarroll, and J. W. Dobbie, "Isolation and propagation in vitro of peritoneal mesothelial cells," Peritoneal Dialysis International, vol. 9, no. 4, pp. 341-347, 1989.

[30] A. M. Afify, B. M. Al-Khafaji, A. F. G. Paulino, and R. M. Davila, "Diagnostic use of muscle markers in the cytologic evaluation of serous fluids," Applied Immunohistochemistry and Molecular Morphology, vol. 10, no. 2, pp. 178-182, 2002.

[31] J. Kupryjańczyk and G. Karpińska, "Desmin expression in reactive mesothelium: a potential aid in evaluation of gynecologic specimens," International Journal of Gynecological Pathology, vol. 17, no. 2, pp. 123-128, 1998.

[32] M. Simionescu and N. Sinionescu, "Organization of cell junctions in the peritoneal mesothelium," Journal of Cell Bio$\log y$, vol. 74, no. 1, pp. 98-110, 1977.

[33] T. Ito, N. Yorioka, M. Yamamotcv, K. Kataoka, and M. Yamakido, "Effect of glucose on intercellular junctions of 
cultured human peritoneal mesothelial cells," Journal of the American Society of Nephrology, vol. 11, no. 11, pp. 19691979, 2000.

[34] T. Ito, N. Yorioka, Y. Kyuden et al., "Effect of glucose polymer on the intercellular junctions of cultured human peritoneal mesothelial cells," Neprhon Experimental Nephrology, vol. 93, no. 3, pp. c97-105, 2003.

[35] S. E. Mutsaers, “The mesothelial cell," International Journal of Biochemistry and Cell Biology, vol. 36, no. 1, pp. 9-16, 2004.

[36] S. E. Mutsaers and S. Wilkosz, "Structure and function of mesothelial cells," Cancer Treatment and Research, vol. 134, pp. 1-19, 2007.

[37] S. Yung and T. M. Chan, "Mesothelial cells," Peritoneal Dialysis International, vol. 27, no. 2, pp. S110-S115, 2007.

[38] T. C. Laurent, U. B. G. Laurent, and J. R. E. Fraser, "The structure and function of hyaluronan: an overview," Immunology and Cell Biology, vol. 74, no. 2, pp. A1-A7, 1996.

[39] J. R. E. Fraser, T. C. Laurent, and U. B. G. Laurent, "Hyaluronan: its nature, distribution, functions and turnover," Journal of Internal Medicine, vol. 242, no. 1, pp. 27-33, 1997.

[40] N. Itano, T. Sawai, M. Yoshida et al., "Three isoforms of mammalian hyaluronan synthases have distinct enzymatic properties," The Journal of Biological Chemistry, vol. 274, no. 35, pp. 25085-25092, 1999.

[41] T. D. Camenisch, A. P. Spicer, T. Brehm-Gibson et al., "Disruption of hyaluronan synthase-2 abrogates normal cardiac morphogenesis and hyaluronan-mediated transformation of epithelium to mesenchyme," The Journal of Clinical Investigation, vol. 106, no. 3, pp. 349-360, 2000.

[42] A. Jacobson, J. Brinck, M. J. Briskin, A. P. Spicer, and P. Heldin, "Expression of human hyaluronan syntheses in response to external stimuli," Biochemical Journal, vol. 348, no. 1, pp. 29-35, 2000.

[43] T. C. Laurent and J. R. E. Fraser, "Hyaluronan," The FASEB Journal, vol. 6, no. 7, pp. 2397-2404, 1992.

[44] A. Almond, "Hyaluronan," Cellular and Molecular Life Sciences, vol. 64, no. 13, pp. 1591-1596, 2007.

[45] G. M. Campo, A. Avenoso, A. Micali et al., "High-molecular weight hyaluronan reduced renal PKC activation in genetically diabetic mice," Biochimica et Biophysica Acta, vol. 1802, no. 11, pp. 1118-1130, 2010.

[46] D. Jiang, J. Liang, and P. W. Noble, "Hyaluronan in tissue injury and repair," Annual Review of Cell and Developmental Biology, vol. 23, pp. 435-461, 2007.

[47] B. P. Toole, "Hyaluronan promotes the malignant phenotype," Glycobiology, vol. 12, no. 3, pp. 37R-42R, 2002.

[48] P. Heldin, E. Karousou, B. Bernert, H. Porsch, K. Nishitsuka, and S. Skandalis, "Importance of hyaluronan-CD44 interactions in inflammation and tumorigenesis," Connective Tissue Research, vol. 49, no. 3-4, pp. 215-218, 2008.

[49] N. Itano, L. Zhuo, and K. Kimata, "Impact of the hyaluronanrich tumor microenvironment on cancer initiation and progression," Cancer Science, vol. 99, no. 9, pp. 1720-1725, 2008.

[50] B. P. Toole, "Hyaluronan: from extracellular glue to pericellular cue," Nature Reviews Cancer, vol. 4, no. 7, pp. 528-539, 2004.

[51] S. P. Evanko, J. C. Angello, and T. N. Wight, "Formation of hyaluronan- and versican-rich pericellular matrix is required for proliferation and migration of vascular smooth muscle cells," Arteriosclerosis, Thrombosis, and Vascular Biology, vol. 19, no. 4, pp. 1004-1013, 1999.

[52] N. Itano, F. Atsumi, T. Sawai et al., "Abnormal accumulation of hyaluronan matrix diminishes contact inhibition of cell growth and promotes cell migration," Proceedings of the $\mathrm{Na}$ - tional Academy of Sciences of the United States of America, vol. 99, no. 6, pp. 3609-3614, 2002.

[53] A. Zoltan-Jones, L. Huang, S. Ghatak, and B. P. Toole, "Elevated hyaluronan production induces mesenchymal and transformed properties in epithelial cells," The Journal of Biological Chemistry, vol. 278, no. 46, pp. 45801-45810, 2003.

[54] D. Jiang, J. Liang, and P. W. Noble, "Hyaluronan as an immune regulator in human diseases," Physiological Reviews, vol. 91, no. 1, pp. 221-264, 2011.

[55] P. W. Noble, "Hyaluronan and its catabolic products in tissue injury and repair," Matrix Biology, vol. 21, no. 1, pp. 25-29, 2002.

[56] B. Haslinger, S. Mandl-Weber, A. Sellmayer, and T. Sitter, "Hyaluronan fragments induce the synthesis of MCP-1 and IL-8 in cultured human peritoneal mesothelial cells," Cell and Tissue Research, vol. 305, no. 1, pp. 79-86, 2001.

[57] D. C. West, I. N. Hampson, F. Arnold, and S. Kumar, "Angiogenesis induced by degradation products of hyaluronic acid," Science, vol. 228, no. 4705, pp. 1324-1336, 1985.

[58] C. M. McKee, C. J. Lowenstein, M. R. Horton et al., "Hyaluronan fragments induce nitric-oxide synthase in murine macrophages through a nuclear factor $\kappa \mathrm{B}$-dependent mechanism," The Journal of Biological Chemistry, vol. 272, no. 12, pp. 8013-8018, 1997.

[59] C. M. McKee, M. B. Penno, M. Cowman et al., "Hyaluronan (HA) fragments induce chemokine gene expression in alveolar macrophages: the role of HA size and CD44," The Journal of Clinical Investigation, vol. 98, no. 10, pp. 2403-2413, 1996.

[60] C. Fieber, P. Baumann, R. Vallon et al., "Hyaluronanoligosaccharide-induced transcription of metalloproteases," Journal of Cell Science, vol. 117, no. 2, pp. 359-367, 2004.

[61] G. M. Campo, A. Avenoso, S. Campo, A. D’Ascola, G. Nastasi, and A. Calatroni, "Small hyaluronan oligosaccharides induce inflammation by engaging both toll-like- 4 and CD44 receptors in human chondrocytes," Biochemical Pharmacology, vol. 80, no. 4, pp. 480-490, 2010.

[62] N. Guo, X. Li, M. M. Mann, M. L. Funderburgh, Y. Du, and J. L. Funderburgh, "Hyaluronan synthesis mediates the fibrotic response of keratocytes to transforming growth factor $\beta$," The Journal of Biological Chemistry, vol. 285, no. 42, pp. 3201232019, 2010.

[63] S. Yung, G. A. Coles, and M. Davies, "IL-1 $\beta$, a major stimulator of hyaluronan synthesis in vitro of human peritoneal mesothelial cells: relevance to peritonitis in CAPD," Kidney International, vol. 50, no. 4, pp. 1337-1343, 1996.

[64] S. Pasonen-Seppänen, S. Karvinen, K. Törrönen et al., "EGF upregulates, whereas TGF- $\beta$ downregulates, the hyaluronan synthases Has 2 and Has 3 in organotypic keratinocyte cultures: correlations with epidermal proliferation and differentiation," Journal of Investigative Dermatology, vol. 120, no. 6, pp. 1038-1044, 2003.

[65] D. Vigetti, A. Genasetti, E. Karousou et al., "Proinflammatory cytokines induce hyaluronan synthesis and monocyte adhesion in human endothelial cells through hyaluronan synthase 2 (HAS2) and the nuclear factor- $\kappa \mathrm{B}(\mathrm{NF}-\kappa \mathrm{B})$ pathway," The Journal of Biological Chemistry, vol. 285, no. 32, pp. 2463924645, 2010.

[66] H. S. Wang, W. H. Tung, K. T. Tang et al., "TGF- $\beta$ induced hyaluronan synthesis in orbital fibroblasts involves protein kinase C $\beta$ II activation in vitro," Journal of Cellular Biochemistry, vol. 95, no. 2, pp. 256-267, 2005.

[67] M. Averbeck, C. A. Gebhardt, S. Voigt et al., "Differential regulation of hyaluronan metabolism in the epidermal and dermal compartments of human skin by UVB irradiation," 
Journal of Investigative Dermatology, vol. 127, no. 3, pp. 687697, 2007.

[68] C. P. D. Wheeler-Jones, C. E. Farrar, and A. A. Pitsillides, "Targeting hyaluronan of the endothelial glycocalyx for therapeutic intervention," Current Opinion in Investigational Drugs, vol. 11, no. 9, pp. 997-1006, 2010.

[69] J. Roth, "Ultrahistochemical demonstration of saccharide components of complex carbohydrates at the alveolar cell surface and at the mesothelial cell surface of the pleura visceralis of mice by means of concanavalin A," Experimentelle Pathologie, vol. 8, no. 3, pp. 157-167, 1973.

[70] S. P. Evanko, M. I. Tammi, R. H. Tammi, and T. N. Wight, "Hyaluronan-dependent pericellular matrix," Advanced Drug Delivery Reviews, vol. 59, no. 13, pp. 1351-1365, 2007.

[71] A. Kultti, K. Rilla, R. Tiihonen, A. P. Spicer, R. H. Tammi, and M. I. Tammi, "Hyaluronan synthesis induces microvillus-like cell surface protrusions," The Journal of Biological Chemistry, vol. 281, no. 23, pp. 15821-15828, 2006.

[72] F. R. Johnson and H. W. Whitting, "Repair of parietal peritoneum," British Journal of Surgery, vol. 49, pp. 653-660, 1962.

[73] G. Eskeland, "Regeneration of parietal peritoneum in rats. 1. A light microscopical study," Acta Pathologica et Microbiologica Scandinavica, vol. 68, no. 3, pp. 355-378, 1966.

[74] G. Eskeland and A. Kjaerheim, "Regeneration of parietal peritoneum in rats. 2. An electron microscopical study," Acta Pathologica et Microbiologica Scandinavica, vol. 68, no. 3, pp. 379-395, 1966.

[75] S. E. Mutsaers, D. Whitaker, and J. M. Papadimitriou, "Mesothelial regeneration is not dependent on subserosal cells," Journal of Pathology, vol. 190, no. 1, pp. 86-92, 2000.

[76] A. J. Foley-Comer, S. E. Herrick, T. Al-Mishlab, C. M. Prêle, G. J. Laurent, and S. E. Mutsaers, "Evidence for incorporation of free-floating mesothelial cells as a mechanism of serosal healing," Journal of Cell Science, vol. 115, no. 7, pp. 13831389, 2002.

[77] D. Whitaker and J. Papadimitriou, "Mesothelial healing: morphological and kinetic investigations," Journal of Pathology, vol. 145, no. 2, pp. 159-175, 1985.

[78] A. T. Raftery, "Regeneration of parietal and visceral peritoneum: an electron microscopical study," Journal of Anatomy, vol. 115, no. 3, pp. 375-392, 1973.

[79] A. T. Raftery, "Regeneration of parietal and visceral peritoneum: an enzyme histochemical study," Journal of Anatomy, vol. 121, no. 3, pp. 589-597, 1976.

[80] K. N. Lai, C. C. Szeto, K. B. Lai, C. W. K. Lam, D. T. M. Chan, and J. C. K. Leung, "Increased production of hyaluronan by peritoneal cells and its significance in patients on CAPD," American Journal of Kidney Diseases, vol. 33, no. 2, pp. 318324, 1999.

[81] S. Meran, D. Thomas, P. Stephens et al., "Involvement of hyaluronan in regulation of fibroblast phenotype," The Journal of Biological Chemistry, vol. 282, no. 35, pp. 2568725697, 2007.

[82] S. Yung and M. Davies, "Response of the human peritoneal mesothelial cell to injury: an in vitro model of peritoneal wound healing," Kidney International, vol. 54, no. 6, pp. 2160-2169, 1998.

[83] G. Kaya, I. Rodriguez, J. L. Jorcano, P. Vassalli, and I. Stamenkovic, "Selective suppression of CD44 in keratinocytes of mice bearing an antisense CD44 transgene driven by a tissue-specific promoter disrupts hyaluronate metabolism in the skin and impairs keratinocyte proliferation," Genes and Development, vol. 11, no. 8, pp. 996-1007, 1997.
[84] R. Stern, A. A. Asari, and K. N. Sugahara, "Hyaluronan fragments: an information-rich system," European Journal of Cell Biology, vol. 85, no. 8, pp. 699-715, 2006.

[85] S. Yung, Z. H. Liu, K. N. Lai, L. S. Li, and T. M. Chan, "Emodin ameliorates glucose-induced morphologic abnormalities and synthesis of transforming growth factor $\beta 1$ and fibronectin by human peritoneal mesothelial cells," Peritoneal Dialysis International, vol. 21, supplement 3, pp. S41-S47, 2001.

[86] M. Yáñez-Mó, E. Lara-Pezzi, R. Selgas et al., "Peritoneal dialysis and epithelial-to-mesenchymal transition of mesothelial cells," The New England Journal of Medicine, vol. 348, no. 5, pp. 403-413, 2003.

[87] K. Ksiazek, K. Korybalska, A. Jorres, and J. Witowski, "Accelerated senescence of human peritoneal mesothelial cells exposed to high glucose: the role of TGF-beta1," Laboratory Investigation, vol. 87, no. 4, pp. 345-356, 2007.

[88] J. Witowski, K. Ksiazek, and A. Jorres, "New insights into the biology of peritoneal mesothelial cells: the roles of epithelialto-mesenchymal transition and cellular senescence," Nephron Experimental Nephrology, vol. 108, no. 4, pp. e69-e73, 2008.

[89] K. Ksiazek, J. Mikula-Pietrasik, K. Korybalska, G. Dworacki, A. Jorres, and J. Witowski, "Senescent peritoneal mesothelial cells promote ovarian cancer cell adhesion, the role of oxidative stress-induced fibronectin," American Journal of Pathology, vol. 174, no. 4, pp. 1230-1240, 2009.

[90] T. M. Chan, J. K. H. Leung, Y. Sun, K. N. Lai, R. C. W. Tsang, and S. Yung, "Different effects of amino acid-based and glucose-based dialysate from peritoneal dialysis patients on mesothelial cell ultrastructure and function," Nephrology Dialysis Transplantation, vol. 18, no. 6, pp. 1086-1094, 2003.

[91] M. Nieuwdorp, T. W. Van Haeften, M. C. L. G. Gouverneur et al., "Loss of endothelial glycocalyx during acute hyperglycemia coincides with endothelial dysfunction and coagulation activation in vivo," Diabetes, vol. 55 , no. 2 , pp. 480-486, 2006.

[92] A. Breborowicz, A. Polubinska, K. Pawlaczyk et al., "Intraperitoneal hyaluronan administration in conscious rats: absorption, metabolism, and effects on peritoneal fluid dynamics," Peritoneal Dialysis International, vol. 21, no. 2, pp. 130-135, 2001.

[93] A. Połubinska, K. Pawlaczyk, M. Kuzlan-Pawlaczyk et al., "Dialysis solution containing hyaluronan: effect on peritoneal permeability and inflammation in rats," Kidney International, vol. 57, no. 3, pp. 1182-1189, 2000.

[94] T. Wang, C. Chen, O. Heimbürger, J. Waniewski, J. Bergström, and B. Lindholm, "Hyaluronan decreases peritoneal fluid absorption in peritoneal dialysis," Journal of the American Society of Nephrology, vol. 8, no. 12, pp. 1915-1920, 1997.

[95] T. Wang, H. H. Cheng, O. Heimbürger et al., "Hyaluronan decreases peritoneal fluid absorption: effect of molecular weight and concentration of hyaluronan," Kidney International, vol. 55, no. 2, pp. 667-673, 1999.

[96] T. Wang, H. H. Cheng, O. Heimbürger, J. Waniewski, J. Bergström, and B. Lindholm, "Hyaluronan prevents the decreased net ultrafiltration caused by increased peritoneal dialysate fill volume," Kidney International, vol. 53, no. 2, pp. 496-502, 1998.

[97] A. Brȩborowicz, M. Pyda, J. Moberly, L. Martis, and D. Oreopoulos, "Effect of haluronan-supplemented dialysate on in vitro function of human peritoneal mesothelial cells," American Journal of Nephrology, vol. 24, no. 3, pp. 316-321, 2004. 
[98] L. S. Lam and J. L. Bert, "Hydraulic flow conductivity of hyaluronic acid solutions: effects of concentration and molecular weight," Biorheology, vol. 27, no. 5, pp. 789-795, 1990.

[99] S. Osada, C. Hamada, T. Shimaoka, K. Kaneko, S. Horikoshi, and Y. Tomino, "Alterations in proteoglycan components and histopathology of the peritoneum in uraemic and peritoneal dialysis (PD) patients," Nephrology Dialysis Transplantation, vol. 24, no. 11, pp. 3504-3512, 2009.

[100] N. Topley and J. D. Williams, "Effect of peritoneal dialysis on cytokine production by peritoneal cells," Blood Purification, vol. 14, no. 2, pp. 188-197, 1996.

[101] S. Jones, C. J. Holmes, R. T. Krediet et al., "Bicarbonate/lactate-based peritoneal dialysis solution increases cancer antigen 125 and decreases hyaluronic acid levels," Kidney International, vol. 59, no. 4, pp. 1529-1538, 2001.

[102] J. D. Williams, N. Topley, K. J. Craig et al., "The EuroBalance Trial: the effect of a new biocompatible peritoneal dialysis fluid (balance) on the peritoneal membrane," Kidney International, vol. 66, no. 1, pp. 408-418, 2004.

[103] L. N. Nejsum and W. J. Nelson, "Epithelial cell surface polarity: the early steps," Frontiers in Bioscience, vol. 14, pp. 1088-1098, 2009.

[104] F. Van Roy and G. Berx, "The cell-cell adhesion molecule Ecadherin," Cellular and Molecular Life Sciences, vol. 65, no. 23, pp. 3756-3788, 2008.

[105] F. Wirtz-Peitz and J. A. Zallen, "Junctional trafficking and epithelial morphogenesis," Current Opinion in Genetics and Development, vol. 19, no. 4, pp. 350-356, 2009.

[106] Y. Xu and Q. Yu, "E-cadherin negatively regulates CD44hyaluronan interaction and CD44-mediated tumor invasion and branching morphogenesis," The Journal of Biological Chemistry, vol. 278, no. 10, pp. 8661-8668, 2003.

[107] S. M. Frisch and R. A. Screaton, "Anoikis mechanisms," Current Opinion in Cell Biology, vol. 13, no. 5, pp. 555-562, 2001.

[108] L. Astachov, R. Vago, M. Aviv, and Z. Nevo, "Hyaluronan and mesenchymal stem cells: from germ layer to cartilage and bone," Frontiers in Bioscience, vol. 16, no. 1, pp. 261-276, 2011.

[109] A. H. Yang, J. Y. Chen, and J. K. Lin, "Myofibroblastic conversion of mesothelial cells," Kidney International, vol. 63, no. 4, pp. 1530-1539, 2003.

[110] P. J. Margetts, P. Bonniaud, L. Liu et al., "Transient overexpression of TGF- $\beta 1$ induces epithelial mesenchymal transition in the rodent peritoneum," Journal of the American Society of Nephrology, vol. 16, no. 2, pp. 425-436, 2005.

[111] E. A. Craig, P. Parker, and T. D. Camenisch, "Size-dependent regulation of Snail2 by hyaluronan: its role in cellular invasion," Glycobiology, vol. 19, no. 8, pp. 890-898, 2009.

[112] L. Alaniz, M. García, P. Cabrera et al., "Modulation of matrix metalloproteinase- 9 activity by hyaluronan is dependent on NF- $\kappa \mathrm{B}$ activity in lymphoma cell lines with dissimilar invasive behavior," Biochemical and Biophysical Research Communications, vol. 324, no. 2, pp. 736-743, 2004.

[113] M. Bruno, P. Gabella, and A. Ramello, "Use of amino acids in peritoneal dialysis solutions," Peritoneal Dialysis International, vol. 20, supplement 2, pp. S166-S171, 2000.

[114] T. M. Chan and S. Yung, "Studying the effects of new peritoneal dialysis solutions on the peritoneum," Peritoneal Dialysis International, vol. 27, supplement 2, pp. S87-S93, 2007.

[115] E. Garcia-Lopez, B. Lindholm, and A. Tranæus, "Biocompatibility of new peritoneal dialysis solutions: clinical experience," Peritoneal Dialysis International, vol. 20, supplement 5, pp. S48-S56, 2001.
[116] M. Haag-Weber, R. Krämer, R. Haake et al., "Low-GDP fluid (Gambrosol trio ${ }^{\circledR}$ ) attenuates decline of residual renal function in PD patients: a prospective randomized study," Nephrology Dialysis Transplantation, vol. 25, no. 7, pp. 22882296, 2010

[117] S. Yung, M. K. M. Ma, K. F. Ng et al., "Impact of a low-glucose peritoneal dialysis regime on inflammatory and fibrotic mediators in effluent dialysate," Journal of the American Society of Nephrology, vol. 22, p. 735A, 2011.

[118] E. Honkanen, B. Froseth, and C. Gronhagen-Riska, "Serum hyaluronic acid and procollagen III amino terminal propeptide in chronic renal failure," American Journal of Nephrology, vol. 11, no. 3, pp. 201-206, 1991.

[119] R. Hallgren, A. Engstrom-Laurent, and U. Nisbeth, "Circulating hyaluronate. A potential marker of altered metabolism of the connective tissue in uremia," Nephron, vol. 46, no. 2, pp. 150-154, 1987.

[120] G. W. Lipkin, M. A. Forbes, E. H. Cooper, and J. H. Turney, "Hyaluronic acid metabolism and its clinical significance in patients treated by continuous ambulatory peritoneal dialysis," Nephrology Dialysis Transplantation, vol. 8, no. 4, pp. 357-360, 1993.

[121] C. C. Szeto, T. Y. Wong, K. B. Lai, C. W. Lam, K. N. Lai, and P. K. Li, "Dialysate hyaluronan concentration predicts survival but not peritoneal sclerosis in continous ambulatory peritoneal dialysis," American Journal of Kidney Diseases, vol. 36, no. 3, pp. 609-614, 2000. 


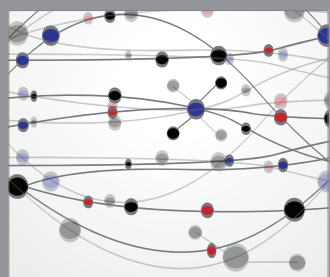

The Scientific World Journal
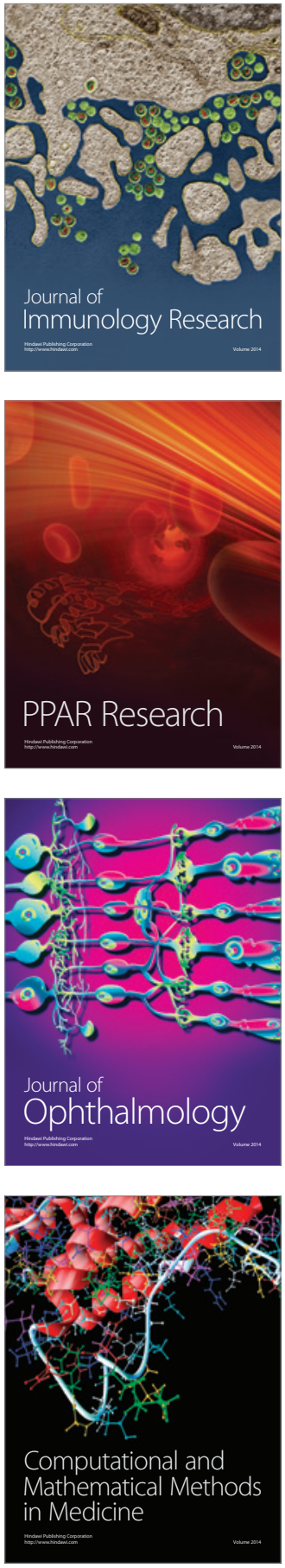

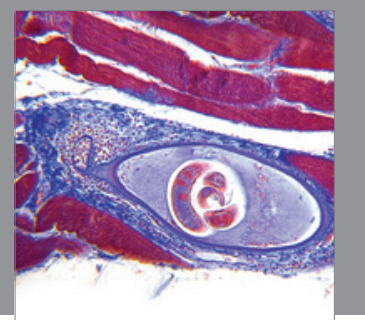

Gastroenterology

Research and Practice
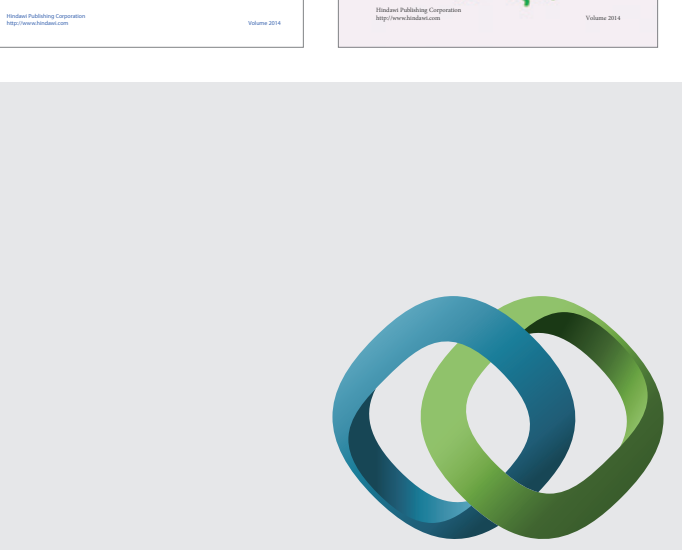

\section{Hindawi}

Submit your manuscripts at

http://www.hindawi.com
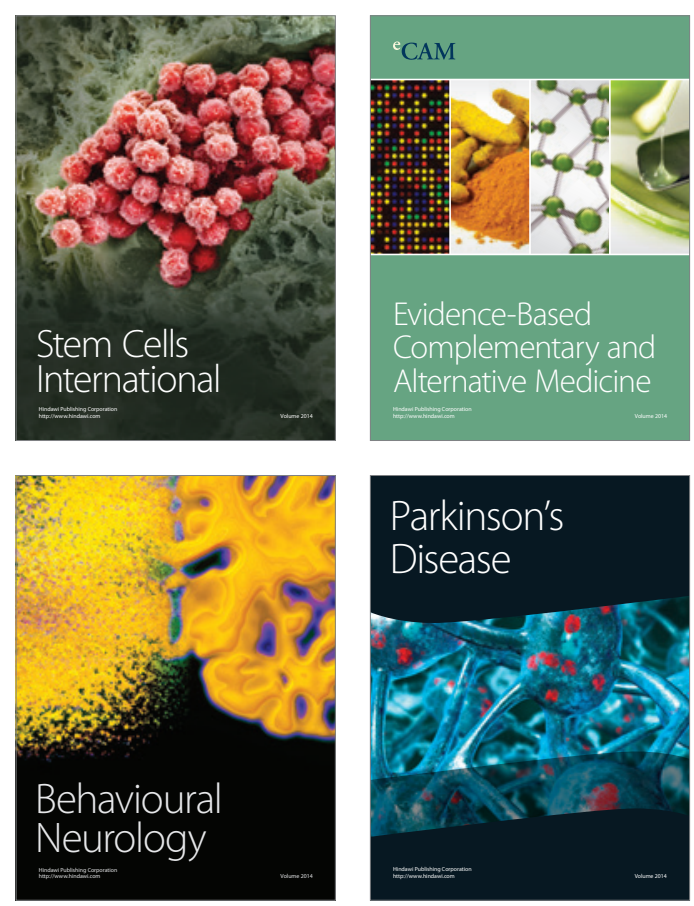

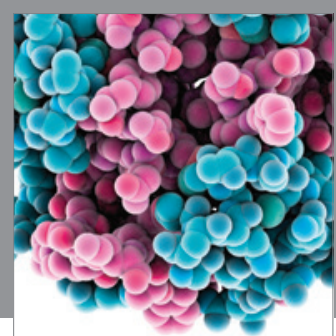

Journal of
Diabetes Research

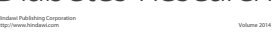

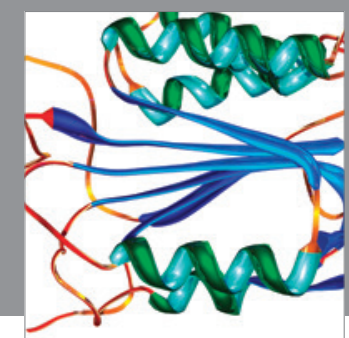

Disease Markers
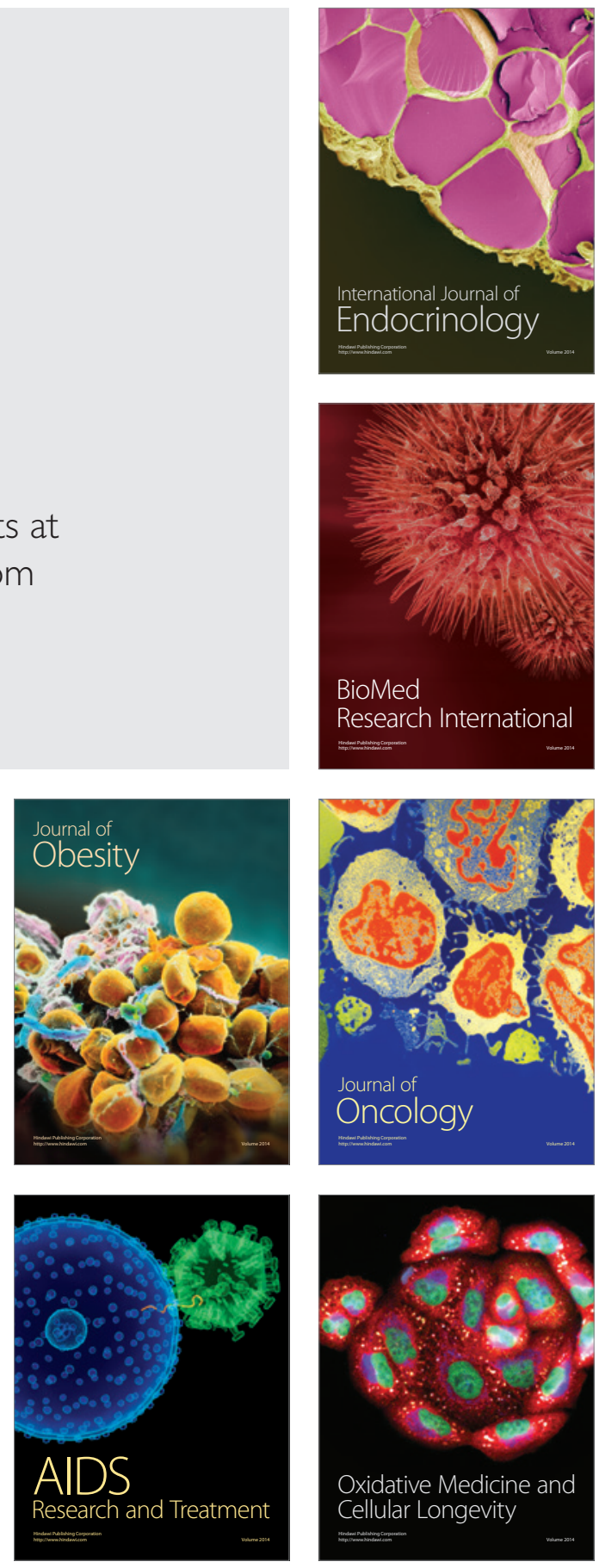